\title{
Producción de biogás con estiércol de cerdo a partir de un biodigestor en la Granja EMAVIMA Jipijapa - Ecuador
}

\section{Production of biogas with pig manure from a biodigester at the EMAVIMA Jipijapa Farm - Ecuador \\ Producción de biogás con estiércol de cerdo a partir de un biodigestor en la Granja EMAVIMA Jipijapa-Ecuador}

\author{
Miguel A. Osejos-Merino ${ }^{\mathrm{I}}$ \\ miguel.osejos@unesum.edu.ec \\ Julio J. Jaramillo-Véliz II \\ julio.jaramillo@unesum.edu.ec \\ Martín V. Merino-Conforme ${ }^{\mathrm{III}}$ \\ martinmerinoconforme@yahoo.es
}

Alex J. Quimis-Gómez ${ }^{\text {IV }}$

alex.quimis@unesum.edu.ec

José L. Alcívar-Cobeña ${ }^{\mathrm{V}}$

jose.alcivar@unesum.edu.ec

Recibido: 27 de octubre de $2017 *$ Corregido: 18 de diciembre de $2017 *$ Aceptado: 02 de enero de 2018

I. Doctor en Ciencias Ambientales, Magister en Docencia mención Gestión en Desarrollo del Currículo, Diplomado en Autoevaluación y Acreditación Universitaria, Biólogo Pesquero, Docente de la Universidad Estatal del Sur de Manabí, Jipijapa, Ecuador.

II. Magister en Sistemas de Información Geográfica Aplicada a la Conservación y Desarrollo Sostenible, Ingeniero Agrícola, Docente de la Universidad Estatal del Sur de Manabí, Jipijapa, Ecuador.

III. Magister en Docencia Universitaria e Investigación Educativa, Diplomado en Autoevaluación y Acreditación Universitaria, Profesor de Segunda Enseñanza Espec. Historia y Geografía; Licenciado en Ciencias de la Educación Especialidad Historia y Geografía; Docente de la Universidad Estatal del Sur de Manabí, Jipijapa, Ecuador.

IV. Magister en Administración Ambiental, Ingeniero en Medio Ambiente, Docente de la Universidad Estatal del Sur de Manabí, Jipijapa, Ecuador.

v. Magister en Gestión Ambiental; Ingeniero Zootecnista; Zootecnista; Docente de la Universidad Estatal del Sur de Manabí, Jipijapa, Ecuador. 


\section{Resumen}

Esta investigación titulada: "Producción de biogás con estiércol de cerdo a partir de un biodigestor en la Granja EMAVIMA Jipijapa - Ecuador”, se basó en que resulta necesario la aplicación de una gestión integral de los residuos orgánicos generado en los establecimientos ganaderos, tomando como objetivo la valorización de los mismos atendiendo a aquellos procesos de reutilización y tratamiento en su forma química, física, biología y energética. La hipótesis fue diseñada para confirmar la producción de biogás, para generar energía mediante el tratamiento biológico del estiércol de cerdos y generar beneficios ambientales en el recinto San Carlos. La metodología utilizada evidencia el cumplimiento de los objetivos y de la hipótesis planteada, los métodos utilizados en esta investigación fueron: bibliográfico, inductivo, deductivo y descriptivo; el tipo de investigación fue de campo y experimental,donde se logró obtener la producción total de estiércol, la cantidad de gas licuado de petróleo (GLP) consumida por año, carga diaria, el volumen en metros cúbicos de producción diaria de biogás. Mediante la generación del biogás se logra atender un problema fundamental en la producción de ganado porcino como es el manejo de desechos y a su vez favorecer el rendimiento económico del establecimiento y reduciendo la contaminación ambiental en el recinto San Carlos de Jipijapa.

Palabras clave: Biogás, estiércol de cerdo, biodigestor, Jipijapa. 


\section{Abstract}

This research entitled: "Production of biogas with pig manure from a biodigester in the Farm EMAVIMA Jipijapa - Ecuador", was based on the need to apply a comprehensive management of organic waste generated in livestock establishments, taking as objective the valorization of the same ones attending to those processes of reuse and treatment in its chemical, physical, biology and energetic form. The hypothesis was designed to confirm the production of biogas, to generate energy through the biological treatment of pig manure and generate environmental benefits in the San Carlos enclosure. The methodology used shows the fulfillment of the objectives and the hypothesis, the methods used in this investigation were: bibliographic, inductive, deductive and descriptive; the type of research was field and experimental, where it was possible to obtain the total production of manure, the amount of liquefied petroleum gas (LPG) consumed per year, daily load, the volume in cubic meters of daily biogas production. Through the generation of biogas it is possible to address a fundamental problem in the production of pigs such as waste management and in turn favor the economic performance of the establishment and reduce environmental pollution in the San Carlos de Jipijapa site.

Keywords: Biogas, pig manure, biodigester, Jipijapa. 


\section{Introducción.}

El uso de digestión anaeróbica para extraer metano de desechos de animales y otros medios como residuos del procesamiento de residuos de animales, produce muchos beneficios; reduce gases invernaderos, reduce el uso de combustibles fósiles, reduce la cantidad de materia orgánica en los rellenos sanitarios. Adicionalmente la producción de biogás es una fuente potencial de ingresos económicos para los agricultores.

La tecnología del biogás se usa prácticamente en todo el mundo, especialmente donde no hay reservas considerables de combustible fósil. La producción de biogás es un proceso que ocurre en forma espontánea, en entorno anaerobio, es decir que carece de oxígeno, dicho proceso lo realizan los microorganismos como parte del ciclo biológico de la materia orgánica, el cual involucra la fermentación o digestión de materiales orgánicos para obtener el biogás.

Los únicos proyectos que se desarrollan son los que está ejecutando el municipio de Cuenca en el relleno sanitario pichacay y Guayaquil en el relleno sanitario las iguanas, para generar energía a través del aprovechamiento de los desechos generado por la ciudadanía.

En Manabí las iniciativas de producir biogás están tomando mayor interés en algunos municipios como es el caso de Santa Ana a partir del reciclaje de los lechuguinos que se genera en la represa poza honda. En Jipijapa el sector agrícola genera grandes cantidades significantes de biomasa incluyendo desecho de animales, vegetales y otros materiales orgánicos que pueden producir energía.

En la actualidad la intensificación porcina está asociada a importantes impactos ambientales, debido principalmente al uso intensivo del recurso suelo y a la eliminación diaria incontrolada de

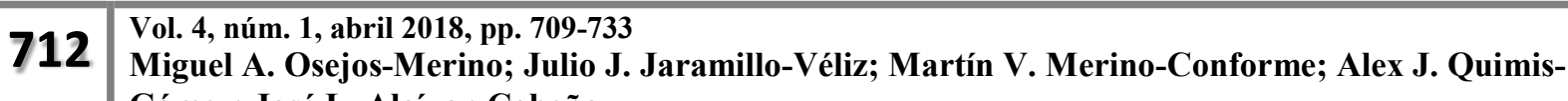
Gómez; José L. Alcívar-Cobeña
} 
efluentes residuales compuestos por estiércol, orina, alimento desperdiciado, agua de bebida y agua de limpieza.

Los estiércoles han ocasionado impactos ambientales negativos como contaminación de suelo, agua, generación de gases que potencializan el efecto invernadero, debido a la falta de información y de manejo de estos insumos. En el caso de algunas familias que tienen cerdos, el manejo es técnicamente inadecuado y además los excrementos se desperdician. Por otra parte al estar dispersos en los terrenos ocasionan situaciones de insalubridad por los malos olores, entre otros; que disminuye la calidad de vida de las personas que se encuentran cerca a esta.

La acumulación de nitrógeno y fosforo que provienen tanto del aire libre como sistemas confinados, y los metales pesados derivados de porcinos en confinamiento puede afectar a la calidad del suelo e incidir en la calidad de cuerpos de aguas cercanos y en el aire.

Los contaminantes más relevantes dentro del grupo de los metales son el cobre el manganeso y el zinc. Sus porciones dependen de la dieta de los cerdos, eliminándose un $86 \%$ de cobre, $95 \%$ de zinc y $79 \%$ de manganeso ingerido en la dieta. (Hatfield \& Stewart, 1997)

Estos elementos son retenidos por las partículas del suelo, pero al ser arrastrados por escorrentía pueden llegar al agua superficial, las aguas subterráneas.

La selección del tema de este proyecto se basó en que resulta necesario la aplicación de una gestión integral de los residuos orgánicos generado en los establecimiento ganaderos, tomando como objetivo la valorización de los mismos atendiendo a aquellos procesos de reutilización y tratamiento en su forma química, física, biología y energética.

\footnotetext{
713 Vol. 4, núm. 1, abril 2018, pp. 709-733 
Una de estas alternativas consiste en la recuperación y aprovechamiento del gas metano componente combustible del biogás, el cual puede obtenerse a través de la degradación biológica anaeróbica de los estiércoles de diversos animales.

Debido a la potencialidad del metano, la recuperación y aprovechamiento de este gas es una actividad prioritaria de los mecanismos de desarrollo limpio, con el propósito de fomentar la reducción de gases de efecto invernadero.

En este trabajo final se justifica al aplicar el tratamiento biológico anaeróbico al estiércol porcino, con el objetivo de determinar los beneficios ambientales que se obtiene de la combinación de estas tecnologías alternativas, para mejorar en la gestión de los residuos generado en los procesos de intensificación ganadera, generando como producto final energía en forma de biogás, que a grandes escalas puede ser utilizado para cubrir diversas necesidades energéticas.

\section{Marco teórico.}

\section{Producción porcina}

La producción porcina intensiva genera cantidades considerables de estiércoles, y su disposición final representa un importante problema ambiental. Aplicaciones no controladas de estiércoles porcinos al suelo, pueden provocar, entre otros exceso de nitratos $\left(\mathrm{N}^{\circ} 3\right)$, sales, metales pesados (cobre y zinc), patógenos, compuestos xenobióticos y emisión de gases de efecto invernadero. (Pro González , 2016)

La expansión de la actividad porcina en el país y el aumento de las tecnologías en el sistema de producción, han dado lugar a un crecimiento en la generación de los desechos que son a menudo

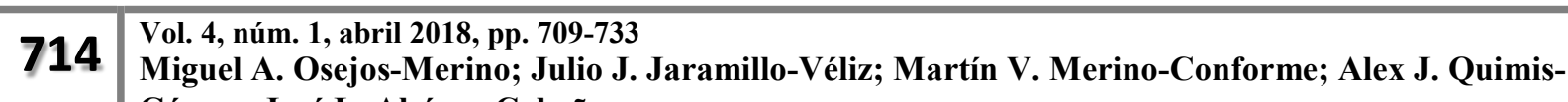
Gómez; José L. Alcívar-Cobeña
} 
lanzados a ríos. Debido a la adopción de sistemas la producción de cerdos confinados, se producen en grandes cantidades los residuos. (Angonese, 2015)

En España una planta de biogás (El Real Decreto RD 661/2007) de 500 KW/h de electricidad tiene un costo de inversión de 1.5 a 2.3 millones de euros, generando uno ingreso por la venta de electricidad de unos 550.000 EUR (8.000 horas de funcionamiento) además se puede obtener ingresos extra por la venta de calor y ciertos residuos industriales. (BENTEC, 2018)

En Pekín existen enormes granjas de gallinas donde producen 212 toneladas de estiércol cada día, el hedor es característico e intenso. Pero esa enorme cantidad de excremento una vez recolectada se lo lleva a una planta procesadora que extrae del abono gas metano para generar electricidad que se vende a la red nacional. (Patience, 2012)

La mayor planta de energía de biogás en Dinamarca es Lemvig Biogas, donde calor y electricidad se generan a partir de estiércol liquido procedente de aproximadamente de 75 explotaciones y desechos y productos residuales de origen industriales, con el biogás producido se genera al año más de 21 millones de KW/h en electricidad, que se vende a la red local. (Lemvig Biogasanlæg , 2018)

Cuando el estiércol es usado con fines agronómicos puede provocar diferentes impactos sobre el suelo y cultivo, dependiendo del sistema de manejo. Es una valiosa fuente de nitrógeno (N), pudiendo sustituir total o parcialmente la fertilización mineral. (Biau, 2012)

La cantidad de metano emitido por el tipo de manejo de desechos es una función de tres factores el tipo de tratamiento o almacenamiento, las condiciones ambientales y la composición del 
estiércol. Los sistemas líquidos producen emisiones de metano mayores a otros sistemas. (EPA, 2015)

La producción de metano también depende del tipo de manejo de estiércol utilizado, en el caso del estiércol del cerdo se utiliza el sistema de manejo líquido incluye lagunas de oxidación, tanques de almacenamiento y pozos profundos. (Eggleston, Buendia, Miwa, Ngara, \& Tanabe, 2006)

La carencia de energía en zonas rurales de energía eléctrica a nivel regional es el principal factor para que se den nuevas alternativas para la producción de energía eléctrica que puedan suplir dicho aumento de la demanda. Los altos precios de combustible y las elevadas tarifas locales de la energía eléctrica son factores fundamentales para desarrollar plantas de biogás a nivel nacional y regional que produzcan energía a partir del uso de los desechos de la producción agropecuaria. (Pezo Valles, Acosta Bedoya, \& Velásquez Piñas, 2011)

\section{Biogás}

El biogás es una mescla de diferentes gases producido por la descomposición anaeróbica de materia orgánica como el estiércol y la basura orgánica, la composición química del biogás indica que el componente más abundante es el metano (CH4); este es el primer hidrocarburo de la serie de alcanos y un gas de efecto invernadero. La mescla de $\mathrm{CH} 4$ con el aire es combustible y arde con llama azul. (Cepero, Savran, Blanco, Díaz Piñón, \& Suárez, 2012)

Este combustible tiene un alto valor calórico de 4700 a $5500 \mathrm{Kcal} / \mathrm{m} 3$ y puede ser utilizado en la cocción de alimentos, para la iluminación de viviendas, así como la alimentación de motores

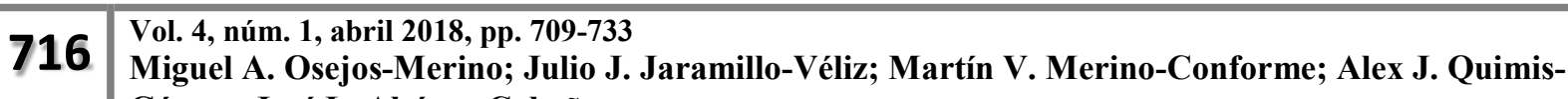
Gómez; José L. Alcívar-Cobeña
} 
de combustión interna que accionan, maquinas herramientas, molinos de granos, generadores eléctricos, bombas de agua y vehículos agrícolas o de cualquier otro tipo. (Villegas Aguilar, 2006)

Según (Martínez Lozano, 2015) en un estudio realizado argumenta que el ganado porcino produce $4 \mathrm{Kg}$. de estiércol fresco por día por cabeza por lo que cada cerdo es capaz de producir 0,33 m3 de biogás útil al día, existen tres opciones empleadas para usar el biocombustible.

- La generación eléctrica: La conversión de la energía contenida en el biogás se hace a través de un motogenerador alimentado por el biogás. La electricidad generada puede alimentar las instalaciones de la explotación agrícola o venderse a la red eléctrica general.

- Uso directo como gas: El biogás es posible también emplearlo de manera directa en los vehículos y maquinaria adaptada para consumo de gas en lugar de gasolina.

- Solución mixta: Es posible optar por solución mixta, empleando parte del biogás para generar electricidad y otra parte utilizada de forma directa.

La descomposición de la materia orgánica en el proceso de digestión anaerobia se divide en 3 etapas, hidrólisis, acidogénesis, metanogénesis. En cada una de las etapas de la descomposición anaeróbica actúan distintas bacterias, estas transforman la materia orgánica en diferentes compuestos como azucares, ácidos grasos hasta llegar a un producto final como el metano. La descomposición anaeróbica convierte los compuestos complejos en compuestos simples, dando como resultado final la liberación de una mescla de gases. (Samayoa, 2012)

La primera etapa es la hidrólisis de partículas y moléculas complejas (proteínas, carbohidratos y lípidos) que son hidrolizadas por encimas extracelulares producidas por los microorganismos acidogénicos o fermentativos. La etapa hidrolítica puede ser el proceso limitante

\footnotetext{
717 Vol. 4, núm. 1, abril 2018, pp. 709-733
Miguel A. Osejos-Merino; Julio J. Jaramillo-Véliz; Martín V. Merino-Conforme; Alex J. Quimis-
Gómez; José L. Alcívar-Cobeña
} 
de la velocidad global sobre todo cuando se tratan residuos con alto contenido de solidos; la hidrolisis depende de la temperatura, del tiempo de retención hidráulico, de la composición bioquímica del sustrato, nivel de ph, de la concentración de metano. (FAO, 2011)

En la segunda etapa, controladas por bacterias consiste en la transformación de los compuestos formados en la primera etapa en otros compuestos de peso molecular intermedio; como dióxido de carbono, hidrogeno, ácidos, alcoholes alifáticos, metilamina, amoniaco y sulfhídrico. (Agrowaste, 2013)

En la metanogénesis es la parte final en el cual la formación de metano, es el último producto de la digestión anaerobia está limitado a tres tipos de precursores: co2, compuesto que contengan un grupo metilo y acetato. Todos los metanogénos son estrictamente arqueas (Archea) anaerobias oxigeno sensibles. Cuando la metanogénesis es mediada por el co2 como precursor se denomina se denomina hidrogenotrófica o hidrogenófila y se utiliza $\mathrm{H} 2$ como principal donador de electrones. (Weber, 2016)

\section{Biodigestor}

Un biodigestor es una cámara hermética e impermeable en la que se depositan desechos orgánicos (estiércol o material vegetal) y agua cruda por un periodo de 35 a 45 días aproximadamente durante los cuales se produce el proceso bioquímico y la acción bacteriana, desarrollándose estas dos simultánea y gradualmente. Todo esto en condiciones ambientales y químicas favorables, en esta acción se descompone la materia orgánica, para luego ser usada como combustible.

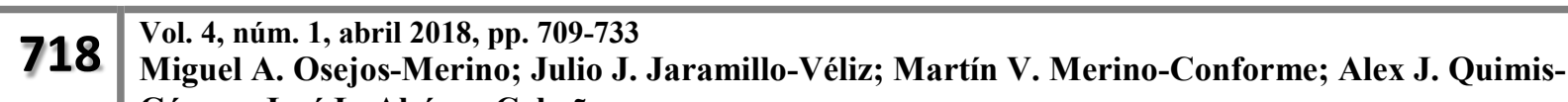
Gómez; José L. Alcívar-Cobeña
} 
La misma autora Domínguez finaliza explicando que un biodigestor puede ser construido de cemento, plástico, dependiendo del recurso económico y pueden ser ubicados de acuerdo al requerimiento y uso de suelo donde se lo ubique.

Un biodigestor anaerobio en un sistema que aprovecha la fermentación de las bacterias presentes en la materia orgánica en ausencia de oxígeno para transformarla y producir biogás y fertilizante, que se lo conoce como biol, es el otro efluente del proceso. Resulta un líquido estabilizado rico en nutrientes. (TOALA MOREIRA, 2013)

La forma de biodigestor de cúpula fija de origen chino, se asemeja a una esfera y el gas se almacena dentro de una capa fina a presión variable, lo cual se obtiene al desplazar el líquido en digestión hacia una cámara llamada de hidropresión; los materiales de construcción son bloques y/o ladrillos, cemento y acero. Estos digestores se cargan en forma semicontinua se realiza una primera carga con material celulósico y estiércol. (Hilbert, 2006)

El biodigestor tubular plástico consiste en una especie de bolsa alongada de polietileno con una relación longitud - ancho de aproximadamente 5.1, aunque por razones de construcción eficientes las dimensiones pueden diferir; dicha bolsa se coloca en un foso. Este biodigestor tiene un costo menor que el anterior pero posee una vida útil inferior. (Cepero, Savran, Blanco, Díaz Piñón, \& Suárez, 2012)

\section{Metodología.}

\section{Ubicación Geográfica de la Investigación}

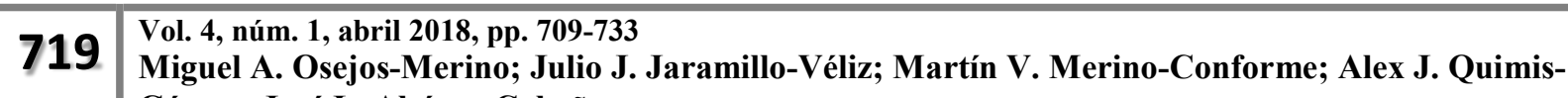
Gómez; José L. Alcívar-Cobeña
} 
La granja porcina EMAVIMA, se encuentra ubicada del recinto "San Carlos" con una longitud $1023^{\prime} 09^{\prime \prime}$ Lat. Sur y 800 30`07“ Long. Oeste. Con una altura de $610 \mathrm{msnm}$

- Método Método bibliográfico: mediante este método se logró conformar el marco teórico y el marco legal de la investigación.

- $\quad$ Inductivo - Deductivo: mediante los resultados obtenidos se logró establecer un manejo adecuado para el estiércol porcino de la granja agrícola.

- Descriptivo: este proceso nos permitió detallar o describir la temática.

Técnicas

Técnicas de análisis de la información: Las técnicas utilizadas en esta investigación posibilitaron la selección de instrumentos adecuados para recabar la información necesaria que permitió obtener resultados concretos y analizar los datos, los cuales proporcionaron los fundamentos teóricos para interpretar la realidad de las variables de estudio.

\section{Tipo de la investigación}

- De campo: Se realizó un diagnóstico sobre la granja en función del estiércol, al igual que el aforo de aproximadamente $360 \mathrm{~kg}$ por día.

- $\quad$ Experimental: Se diseñó un biodigestor

- $\quad$ Descripción del biodigestor

El tipo de biodigestor es continuo, debido a que la biodigestión de la materia prima se desarrolla de manera ininterrumpida, ya que éstos son cargados diariamente y la producción de 
biogás es uniforme en el tiempo. El volumen de efluente que se descarga es igual al del afluente, ya que se mantiene constante.

Este tipo de biodigestor se emplea cuando la materia prima disponible es abundante y su generación es continuada en el tiempo. Una característica importante es la alta dilución de la carga, que en general es de 3 a 5 veces agua/materia prima y, además, su manejo es relativamente fácil.

El diámetro es de seis metros de largo, tres metros de ancho y una profundidad de tres metros.

Gráfico 1. Imagen Satelital de la granja porcina EMAVIMA en el recinto "San Carlos"

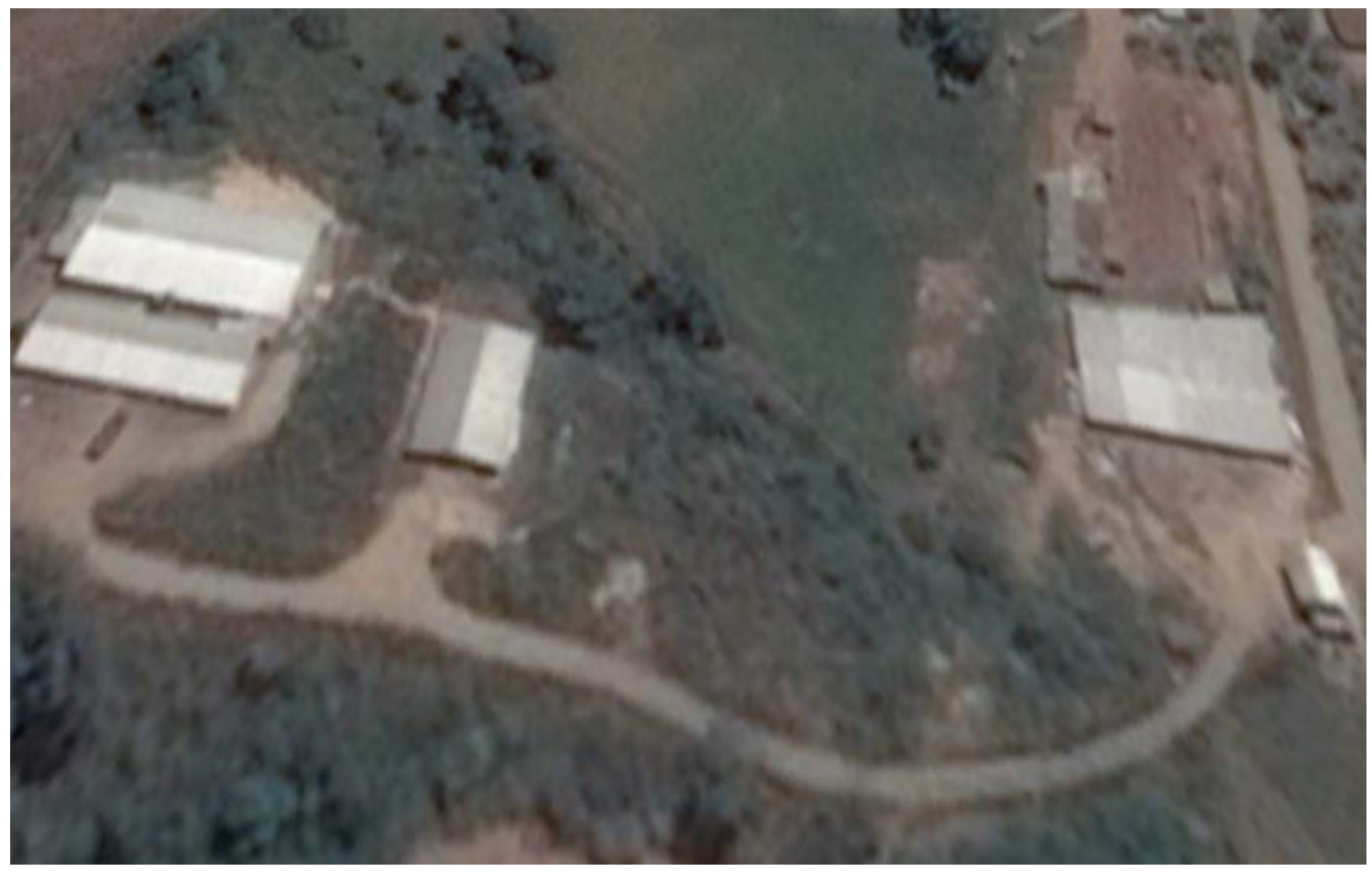

Fuente: Google Earth 


\section{Resultados.}

Para la realización del biodigestor se investigó algunos factores como espacio físico, el consumo mensual de gas licuado de petróleo (GLP), la disponibilidad de materia prima y lo más importante el costo de construcción operación y mantenimiento.

En la granja habitan 20 persona al mes la cual tienen un consumo mensual de 18 tanques de $15 \mathrm{Kg}$ de gas licuado de petróleo (GLP) y un promedio de luz de $347 \mathrm{KWH}$ de energía eléctrica, la granja posee dos chancheras, una chanchera donde se encuentran los lechones con su madre, ubicada en la parte alta de la granja. Una chanchera donde están los cerdos adultos, en esta puede entrar 90 cerdos ubicado en la parte baja de la granja.

Dentro de la realización del biodigestor se encuentran los parámetros que se deben controlar, entre ellos están:

- La cantidad de biogás necesaria.

- La cantidad de estiércol porcino requerido.

Tomando como referencia un estudio realizado en el 2013 por Solar argumenta que el ganado porcino produce $4 \mathrm{Kg}$. de estiércol fresco por día por cabeza por lo que cada cerdo es capaz de producir $0,33 \mathrm{~m} 3$ de biogás útil al día, por lo tanto:

- $\quad$ Si se tienen 90 cerdos de $100 \mathrm{Kg}$, la producción de estiércol fresco (PEF) fue:

- $\quad$ Peso de cerdo adulto $=90$ cerdos adultos $\times 100 \mathrm{Kg}$ de peso 
- $\quad$ Peso de cerdos adultos $=9000 \mathrm{Kg}$ de peso de los cerdos adultos

- $\quad \mathrm{PEF}=9000$ peso por cerdo $\mathrm{x}(4 \mathrm{Kg}$ de estiércol de cerdo $) /(100 \mathrm{Kg}$ peso cerdo $)=360 \mathrm{Kg}$ de estiércol fresco

La producción total de estiércol fue de $360 \mathrm{Kg}$ de estiércol fresco.

Con los resultados obtenidos anteriormente, se tomó en cuenta varios factores para la realización del biodigestor a escala de la granja.

La dimensión del digestor se pudo determinar a base del tiempo de retención y la cantidad de estiércol suministrado diariamente.

La temperatura es una de las ventajas en donde se realizó este parámetro ya que es considerado como tropical y su temperatura se encuentra entre 22 a $350 \mathrm{C}$.

Tiempo de retención para la digestión de una buena digestión anaerobia se consideró un tiempo de retención de aproximadamente 20 días.

Estos dos últimos puntos se encuentran en la siguiente tabla.

Tabla 1. Tiempo de retención según su temperatura

\begin{tabular}{|c|c|c|}
\hline Región características & Temperatura $\left.\mathbf{(}^{\mathbf{0}} \mathbf{C}\right)$ & Tiempo de retención (días) \\
\hline Trópico & 30 & 20 \\
\hline Valle & 20 & 30 \\
\hline Altiplano & 10 & 60 \\
\hline
\end{tabular}

Fuente: Herrero, 2008 
El lugar de instalación del biodigestor se encuentra cerca de la chanchera, mientras la distancia de la casa al biodigestor es de 22 metros, para escoger el diseño del biodigestor se tomó en cuenta el biodigestor de tipo continuo.

Después de obtener el diseño del biodigestor, se calculó los componentes que influyen en el biodigestor, entre ellos:

La cantidad de energía consumida mensualmente en la granja

\section{Cantidad de gas licuado de petróleo (GLP) consumida (CGLP)}

Mensualmente en la granja se consume alrededor de 18 tanques de GLP, cada tanque tiene $15 \mathrm{Kg}$, entonces:

$\mathrm{CGLP}=18$ tanques de $15 \mathrm{Kg}$ GLP $=18 \times 15=270 \mathrm{Kg}$ de GLP $/$ mes.

Se desea obtener el consumo de Kg de GLP al año, entonces:

$\frac{270 \mathrm{Kg} \text { de GLP }}{\text { Mes }} \times \frac{12 \text { Meses }}{1 \text { Año }}=3240 \mathrm{de} \mathrm{GLP/} \mathrm{año}$

La cantidad de estiércol requerido

Se tomó en cuenta los cálculos realizados en la página 15, en donde los 90 cerdos producen $360 \mathrm{Kg}$ de estiércol fresco (EF) diario.

Para la alimentación del biodigestor se usó una mescla de estiércol más agua, con una relación 1:1 según Monar (s/f), se asumió que un $\mathrm{Kg}$ de $\mathrm{EF}=1$ Lt EF entonces se tiene:

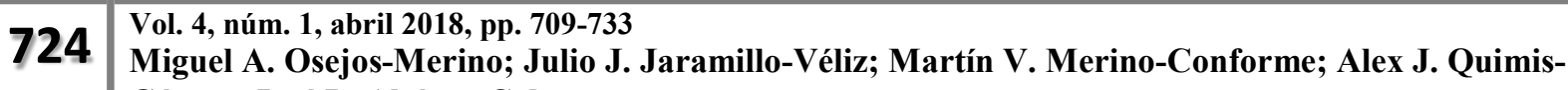
Gómez; José L. Alcívar-Cobeña
} 
Carga diaria $(\mathrm{CD})=\mathrm{EF}+$ agua $=\frac{360 \mathrm{Kg} \text { de } \mathrm{EF}}{\text { dia }} x \frac{1 \mathrm{~L}}{1 \mathrm{Kg}}+\frac{360 \mathrm{~L}}{\text { dia }}$

Carga diaria $(C D)=720 \mathrm{~L}$ de mescla/ día $=0,720 \mathrm{~m}^{3}$ de mescla/ día

Diseño de un biodigestor según disponibilidad de estiércol

Se calculó el volumen que debe tener el biodigestor tomando en cuenta el tiempo de retención en la tabla 1. Entonces para una producción se obtuvo que el Tiempo de Retención (TR) sea de 20 días.

Vol. liquido $=(\mathrm{CD}) \times(\mathrm{TR})$

Vol. liquido $=\left(0,720 \mathrm{~m}^{3} /\right.$ día $) \times(20$ días $)$

Vol. liquido $=1440 \mathrm{~m}^{3}=14400 \mathrm{~L}$

El volumen total del biodigestor ha de albergar una parte liquida y otra gaseosa.

Normalmente se da un espacio del $75 \%$ del volumen total a la fase liquida, y del $25 \%$ restante a la fase gaseosa, entonces:

Vol. gaseoso $=$ Vol. total $\times 0,25$

Vol. gaseoso $=($ Vol. gaseoso +14400$) \times 0,25$

Vol. gaseoso $=0,25$ Vol. gaseoso +3600

Vol. gaseoso $=0,25$ Vol. gaseoso $=3600$ 
0,75 Vol. gaseoso $=3600$

Vol. gaseoso $=3600 / 0,75$

Vol. gaseoso $=4800 \mathrm{~L}=4800 \mathrm{~m}^{3}$

Finalmente el volumen total fue:

$\mathrm{V}_{\mathrm{t}}=\mathrm{v}_{\mathrm{L}}+\mathrm{v}_{\mathrm{G}}$

$\mathrm{V}_{\mathrm{t}}=14400+4800$

$V_{t}=19200 \mathrm{~L}=19,20 \mathrm{~m}^{3}$

Para calcular la producción diaria de biogás

Donde

$\mathrm{PG}=\mathrm{Gas}$ producido en litro por día

$\mathrm{MPC}=$ Estiércol en kilogramos por día

$\mathrm{SO}=$ porcentaje de materia orgánica según la especie

$\mathrm{P}=$ producción aproximada de $\mathrm{m}^{3}$ de gas según la especie

$\mathrm{PG}=\mathrm{MPC} \times \mathrm{SO} \times \mathrm{P}$

$\mathrm{PG}=360 \times 4 \times 29.7$

$\mathrm{PG}=42768 \mathrm{~m}^{3}$ 
Antes del proceso de construcción se consideró los siguientes aspectos:

- El biodigestor debe encontrarse cercano a la zona donde se recoge el sustrato de partida y a la zona de consumo.

- Debe mantenerse a una temperatura constante y cercana a $\operatorname{los} 35^{\circ} \mathrm{C}$

- Se necesita acumular el estiércol cerca del biodigestor.

- Recursos disponibles de tipos económicos, materiales de construcción, mano de obra.

- La Localización y la geografía, aspectos como latitud, longitud y altitud.

\section{Proceso de construcción}

1. Se seleccionó el tipo de biodigestor de acuerdo a la frecuencia de alimentación y a la necesidad de descarga total o parcial del sustrato digerido.

2. Para la selección del lugar trazado y excavación, se socializo con el administrador de la granja, la cual se instaló adjunto del lugar de la materia prima. Y el diámetro fue de seis metros de largo, tres metros de ancho y una profundidad de 3 metros.

3. El costo de la construcción, mano de obra y materiales, fueron asumidos por el administrador de la granja. Para el cubrimiento y los materiales de PVC el costo fue de 200 dólares.

4. Se colocaron los ductos para que la descarga de orín más agua pase directamente al tanque de concreto.

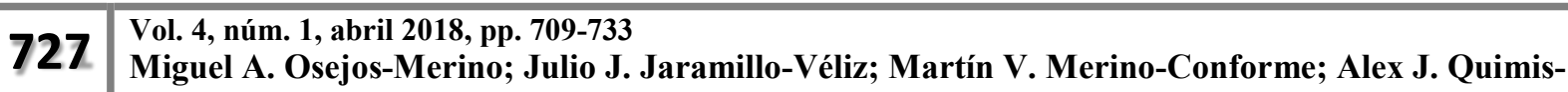
Gómez; José L. Alcívar-Cobeña
} 
5. La carga se la realiza de manera diaria.

6. El tiempo de duración del biodigestor es de 5 años.

Para el cubrimiento se utilizaron los siguientes materiales:
$\checkmark \quad 32$ metros de plástico
$\checkmark \quad 1 / 2$ tubo de 2 pulgadas
$\checkmark \quad 1$ codo de 2 pulgadas
$\checkmark \quad 1$ sifón de 2 pulgadas
$\checkmark \quad 2$ codo de $2 \times 45$
$\checkmark \quad 1$ tapón de 2 pulgadas
$\checkmark \quad 1$ ciento de tronillos de $2 \times 6$
$\checkmark \quad 1$ tubo de silicón
$\checkmark \quad 1$ unión d de 2 pulgadas
$\checkmark \quad 30$ tornillos de $1 \frac{1}{2}$
$\checkmark \quad 30 \operatorname{tacos} \# 6$ 
$\checkmark \quad 1$ cemento de contacto

Operación del biodigestor y uso del biogás. Descripción del proceso:

Molienda: Es recomendable moler el estiércol fresco que se va a utilizar para la digestión, ya que al disminuir el tamaño de los sólidos se está aumentando el área de contacto con los microorganismos encargados de iniciar el proceso. En caso de que no se encuentre un equipo para la molienda, esta etapa puede pasar inadvertida. Tomando en cuenta lo anterior, el siguiente paso es vaciar el estiércol en un recipiente adecuado para el acondicionamiento o bien se puede hacer directamente al biodigestor.

Válvula de salida de biogás: Es la llave que comunica la salida de biogás con la red de distribución para consumo. También es llamada válvula de seguridad, ya que permite cerrar el paso de biogás a esta red, en caso de detectar alguna pérdida. Se recomienda colocar otras válvulas de paso al inicio de éstas para evitar el cierre generalizado ante operaciones de mantenimiento o reparación. Se recomienda que todas las llaves empleadas sean de un material resistente a la corrosión, debido a la presencia de vapor de agua y ácido sulfhídrico en la composición del biogás.

Carga del biodigestor: La carga se hará a través de un motor, la operación del biodigestor resulta muy sencilla, continuación se describe el proceso:

a) Verificar que las válvulas estén cerradas.

b) Abrir la válvula de descarga del biogás con el fin de purgar al equipo

c) Abrir la válvula de alimentación. 
d) Alimentar al biodigestor.

e) Cerrar las válvulas de descarga del biogás y la alimentación, después de haber cargado toda la alimentación

f) Purgar diariamente el biogás producido por la válvula de descarga del biogás con el propósito de eliminar la más mínima presencia de aire, así como algo de vapor de agua y de $\mathrm{CO}_{2}$ que se hayan formado.

g) Verificar a la salida si hay combustión de gas.

La producción de gas funciona como indicador, tanto de la condición de cultivo, como de la eficiencia del desempeño del biodigestor. La producción de gas normalmente se expresa en volumen.

El volumen esperado de gas por unidad de materia orgánica es función del tiempo de retención y otras características operacionales, así como de la naturaleza de los desechos.

La producción de gas es un parámetro particularmente útil, pues es fácil reconocer, además de que da una respuesta inmediata a una condición adversa.

La gran variedad de biomasas existentes unidas al desarrollo de distintas tecnologías de transformación de está en energía (combustión directa, pirólisis, gasificación, digestión anaeróbica, etc.) permiten plantear una gran cantidad de posibles aplicaciones entre las que destacan la producción de energía térmica, eléctrica.

Usos del biogás: el biogás se lo utilizara para:

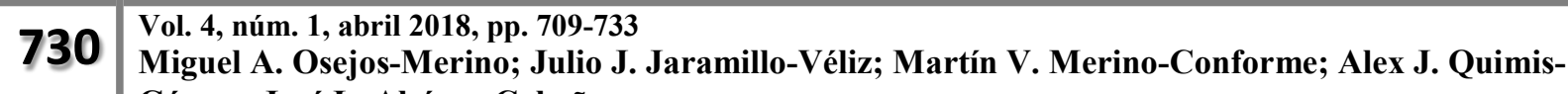
Gómez; José L. Alcívar-Cobeña
} 
- Generar electricidad.

- $\quad$ Iluminación de las lámparas.

- $\quad$ Chimeneas de calor para las crías.

Problemáticas y propuesta de solución

Por falta de presupuesto no se construyó el cerco perimétrico del biodigestor para prevenir el daño por ingreso de animales. La ubicación cercana del Biodigestor a los comederos del establo lechero facilitó el ingreso de un vacuno al Biodigestor que rompió la membrana del mismo provocando la ruptura aproximadamente 5 metros de longitud ocasionando daños irreparables.

Es indispensable construir un cerco perimétrico; con esto se garantizará mantener la seguridad de los equipos como también de los productos obtenidos en el biodigestor.

Se sugirió la construcción de un techo para la protección del reservorio para evitar las altas precipitaciones.

\section{Conclusiones}

La carencia de conocimiento sobre el manejo de fuentes orgánicas y diseños adecuados de biodigestores a nivel nacional, para un adecuado manejo de estiércol de cerdo, dificulta crear industrias que generen trabajo.

El diseño del biodigestor que se instaló en la empresa EMAVIMA es de tipo continúo.

Para poner en funcionamiento el biodigestor, se calculó la cantidad de estiércol requerido. 
La adopción de las técnicas y los resultados depende de aspectos como localización y la manera en que la tecnología se introduce, adapta y mejora según las condiciones locales y técnicas.

El biodigestor contribuye a la disminución y a la acumulación de estiércol a los alrededores de la granja.

La eficiencia de esta tecnología en la resolución de problemas en materia del medio ambiente, especialmente su funcionalidad en este caso será, el medio de difusión más eficaz, para que en el corto o mediano plazo, se generalice la implantación de esta sencilla tecnología.

\section{Agradecimientos.}

Agradecemos a las autoridades de la Universidad Estatal del Sur de Manabí (UNESUM), por el apoyo en esta investigación.

\section{Bibliografía.}

Agrowaste. (2013). DIGESTIÓN ANAEROBIA. Unión Europea: Auotor.

Angonese, A. (2015). Eficiencia energética de sistemas de producción de suínos con tratamiento de residuo en biodigestor. Revista Brasileira de Engenharia Agrícola e Ambiental, 10(3), 745750.

BENTEC. (15 de 03 de 2018). Plantas de Biogas. Obtenido de http://bentec.es/esp/files/Bentec\%20Bioenergies_ESP_0112_opt.pdf

Biau, A. (2012). El impacto de fertilizantes orgánicos y minerales en los parámetros de calidad del suelo y la productividad de los cultivos de maíz de regadío en las regiones semiáridas. Revista Europea de Biología del Suelo, 20(15), 35-45.

Cepero, L., Savran, V., Blanco, D., Díaz Piñón, M., \& Suárez, J. (2012). Producción de biogás y bioabonos a partir de efluentes de biodigestores. Pastos y Forrajes, 35(2), 219-226.

Eggleston, H., Buendia, L., Miwa, K., Ngara, T., \& Tanabe, K. (2006). Directrices del IPCC para los inventarios nacionales de gases de efecto invernadero. Japón: IPPCC. 
EPA. (2015). Inventario de Emisiones de Gases de Efecto Invernadero de Estados Unidos y Sumideros: 1990-2006. Washington: Agencia de Protección Ambiental de EE.UU.

FAO. (2011). Manual de biogás. Santiago de Chile,: Organización de las Naciones Unidas para la Alimentación y la Agricultura.

Hatfield, J., \& Stewart, B. (1997). Animal Waste Utilization: Effective Use of Manure as a Soil Resource. Boca Raton: CRC Press.

Hilbert, J. (2006). MANUAL PARA LA PRODUCCION DE BIOGAS. Buenos Aires: Instituto Nacional de Tecnología Agropecuaria.

Lemvig Biogasanlæg . (02 de 03 de 2018). Lemvig Biogas: Energía renovable y economía sólida. Obtenido de http://www.lemvigbiogas.com/ES.htm

Martínez Lozano, M. (2015). Producción potencial de biogás empleando excretas de ganado porcino en el estado de Guanajuato. Nova Scientia, 7(15), 96-115.

Patience, M. (25 de 6 de 2012). Estiércol de gallinas para impulsar la economía china. BBC, pág. http://www.bbc.com/mundo/noticias/2012/06/120625_china_pollos_energia_am.

Pezo Valles, A., Acosta Bedoya, F., \& Velásquez Piñas, J. (2011). Producción de Energía Renovable (biogás) a partir del estiércol del ganado bovino en la Estación Experimental Agraria El Porvenir - INIA. Análisis de situación actual y mejoras. Navarra: Centro de Información en Energías Renovables.

Pro González , F. (2016). Valoración de efectos ecotoxicológicos de oxitetraciclina en organismos. Departamento de Toxicología y Farmacología. Madrid: Universidad Complutense de Madrid.

Samayoa, S. (2012). Guía implementación de sistemas de biodigestión en ecoempresas. Honduras: SNV.

TOALA MOREIRA, E. (2013). DISEÑO DE UN BIODIGESTOR DE POLIETILENO PARA LA OBTENCIÓN DE BIOGÁS A PARTIR DEL ESTIÉRCOL DE GANADO EN EL RANCHO VERÓNICA. Riobamba: Escuela Superior Politécnica de Chimborazo.

Villegas Aguilar, P. (2006). Development and perspectives of biogas technology in underdeveloped countries. IV International Workshop on Energy and Environment. Cuba: Cienfuegos.

Weber, B. (2016). Producción de biogás en México. México: Red Mexicana de Bioenergía. 